\title{
A Cost-of-Illness analysis of $\beta$-Thalassaemia major in children in Sri Lanka
}

\section{CURRENT STATUS: UNDER REVIEW}

BMC Pediatrics BMC series

Hamish Reed-Embleton

The University of Sheffield

Savinda Arambepola

Hemas Hospital Colombo

Simon Dixon

The University of Sheffield

Behrouz Nezafat Maldonado

Liverpool School of Tropical Medicine

Anuja Premawardhena

University of Kelaniya Faculty of Medicine

\ premawa@hotmail.comCorresponding Author

ORCiD: https://orcid.org/0000-0003-0605-9081

Mahinda Arambepola

National Hospital Kandy

Jahangir A. M. Khan

Liverpool School of Tropical Medicine

Stephen Allen

Liverpool School of Tropical Medicine

DOI:

$10.21203 / \mathrm{rs} .2 .22280 / \mathrm{v} 1$

SUBJECT AREAS

Pediatrics

KEYWORDS

Sri Lanka, Thalassaemia, Cost-of-illness, Children 
Abstract

Background Sri Lanka has a high prevalence of $\beta$-thalassaemia major. Clinical management is complex and long-term and includes regular blood transfusion and iron chelation therapy. The economic burden of $\beta$-thalassaemia for the Sri Lankan healthcare system and households is currently unknown.

Methods A prevalence-based, cost-of-illness study was conducted on the Thalassaemia Unit, Department of Paediatrics, Kandy Teaching Hospital, Sri Lanka. Data were collected from clinical records, consultations with the head of the blood bank and a consultant paediatrician directly involved with the care of patients, alongside structured interviews with families to gather data on the personal costs incurred such as those for travel.

Results Thirty-four children aged 2-17 years with transfusion dependent thalassaemia major and their parent/guardian were included in the study. The total average cost per patient year to the hospital was \$US 2601 of which \$US 2092 were direct costs and \$US 509 were overhead costs. Mean household expenditure was \$US 206 per year with food and transport per transfusion (\$US 7.57 and \$US 4.26 respectively) being the highest cost items. Nine (26.5\%) families experienced catastrophic levels of healthcare expenditure ( $>10 \%$ of income) in the care of their affected child. The poorest households were the most likely to experience such levels of expenditure.

\section{Full-text}

Due to technical limitations, full-text HTML conversion of this manuscript could not be completed. However, the manuscript can be downloaded and accessed as a PDF.

Figures 


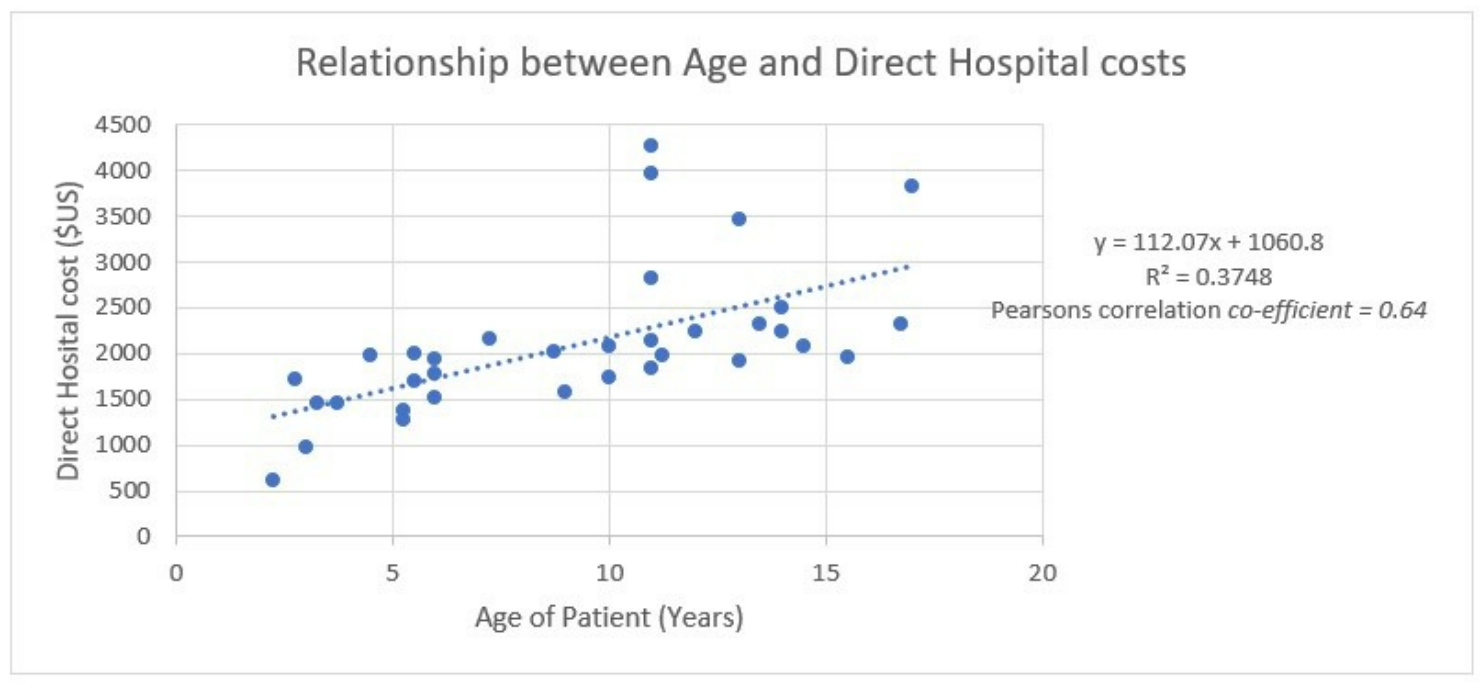

Figure 1

Relationship between age and direct hospital costs. $y=112.07 x+1060.8 R^{2}=0.3748$.

Pearsons correlation co-efficient $=0.64$ 


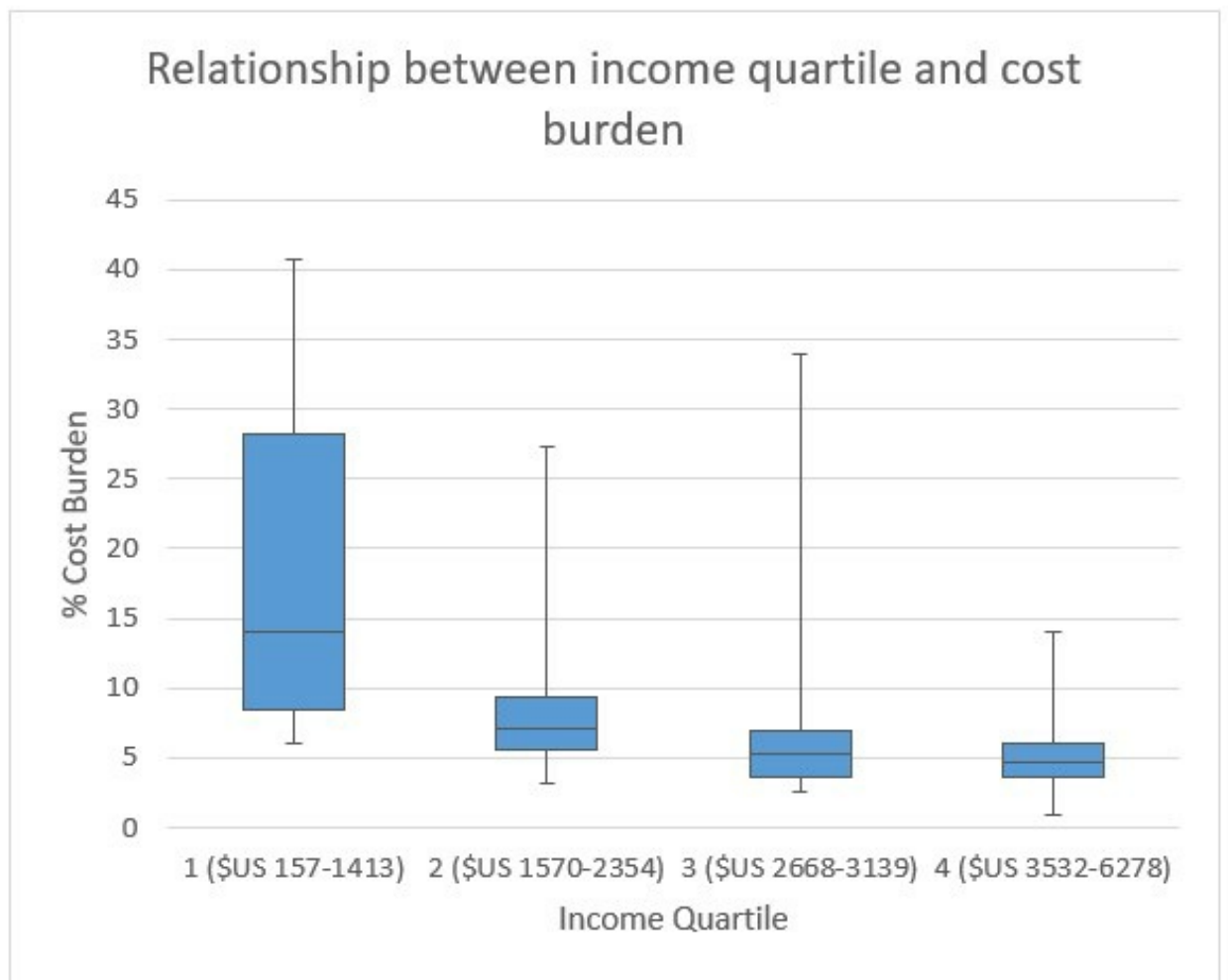

Figure 2

Relationship between income quartile and cost burden. Boxes show Median and IQR, whiskers show range. 


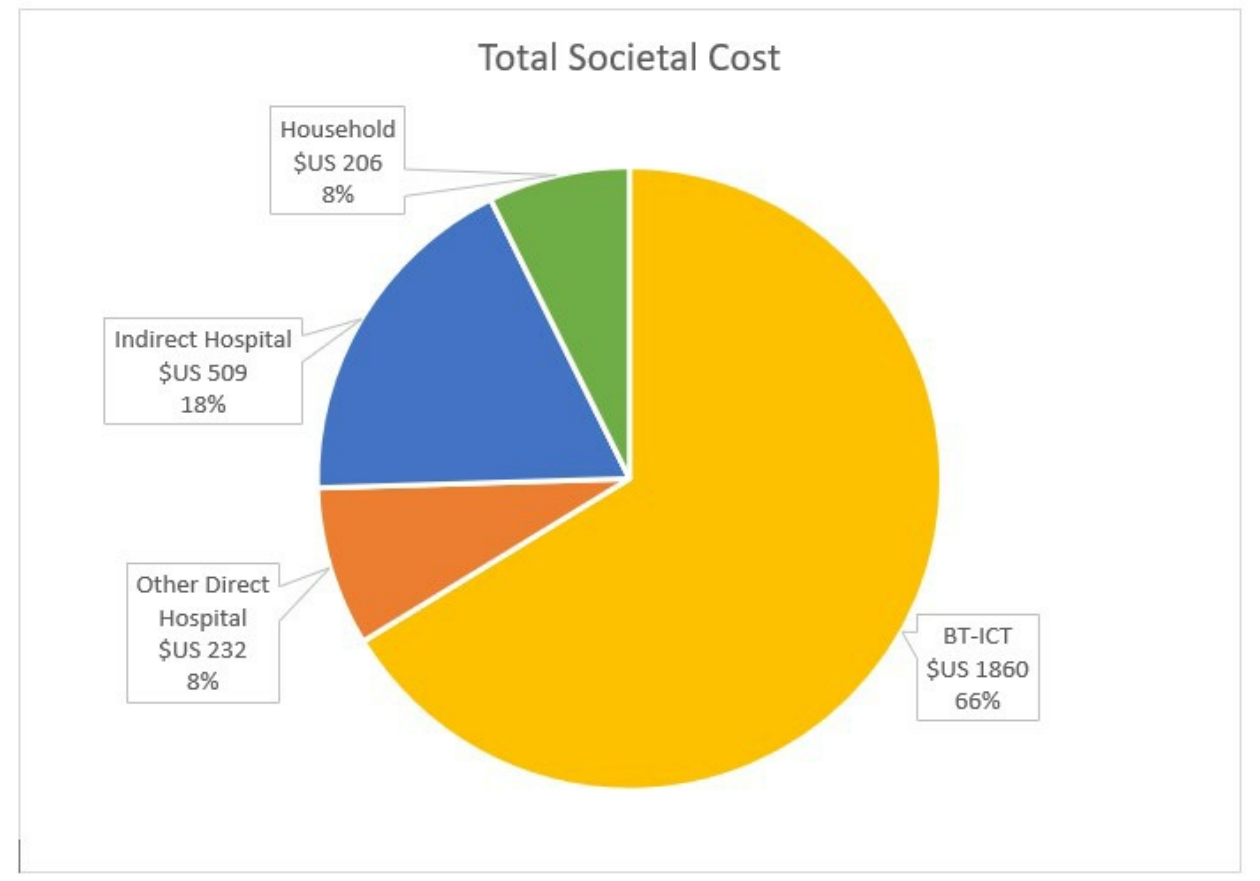

Figure 3

Total societal cost. Values are reported in \$US and expressed as a percentage of the total societal cost 